\title{
THE
}

\section{Equilibration of Baroclinic Meanders and Deep Eddies in a Gulf Stream-type Jet over a Sloping Bottom}

\author{
Georgi G. Sutyrin \\ University of Rhode Island, gsutyrin@uri.edu \\ Isaac Ginis \\ University of Rhode Island, iginis@uri.edu
}

Sergey A. Frolov

Follow this and additional works at: https://digitalcommons.uri.edu/gsofacpubs

\section{Citation/Publisher Attribution}

Sutyrin, G. G., Ginis, I., \& Frolov, S. A. (2001). Equilibration of Baroclinic Meanders and Deep Eddies in a Gulf Stream-type Jet over a Sloping Bottom. Journal of Physical Oceanography, 31, 2049-2065. doi: 10.1175/1520-0485(2001)0312.0.C0;2 Available at: https://doi.org/10.1175/1520-0485(2001)0312.0.c0;2

This Article is brought to you for free and open access by the Graduate School of Oceanography at DigitalCommons@URI. It has been accepted for inclusion in Graduate School of Oceanography Faculty Publications by an authorized administrator of DigitalCommons@URI. For more information, please contact digitalcommons-group@uri.edu. 


\title{
Equilibration of Baroclinic Meanders and Deep Eddies in a Gulf Stream-type Jet over a Sloping Bottom
}

\author{
Georgi G. Sutyrin, IsaAC Ginis, and Sergey A. Frolov \\ Graduate School of Oceanography, University of Rhode Island, Narragansett, Rhode Island
}

(Manuscript received 13 December 1999, in final form 21 September 2000)

\begin{abstract}
Spatiotemporal evolution of a small localized meander on a Gulf Stream-type baroclinically unstable jet over a topographic slope is investigated numerically using a three-dimensional, primitive equation model. An unperturbed jet is prescribed by a potential vorticity front in the upper thermocline overlaying intermediate layers with weak isentropic potential vorticity gradients and a quiscent bottom layer over a positive (same sense as isopycnal tilt) cross-stream continental slope. A series of numerical experiments with the same initial conditions over a slope and flat bottom on the $\beta$ plane and on the $f$ plane has been carried out.

An initially localized meander evolves into a wave packet and generates deep eddies that provide a positive feedback for the meander growth. Meanders found growing over a flat bottom are able to pinch off resembling warm and cold core rings, while in the presence of a weak bottom slope such as 0.002 , the maximum amplitudes of meanders and associated deep eddies saturate with no eddy shedding. In the flat bottom case, the growth rate is only $10 \%$ larger than in the weak slope case. Nevertheless, the bottom slope efficiently controls nonlinear saturation of meander growth via constraining the development of deep eddies. The topographic slope modifies the evolution of deep eddies and causes the phase displacement of deep eddies in the direction of the upper layer troughs/crests, thus limiting growth of the meanders. Behind the wave packet peak deep eddies form a nearly zonal circulation that stabilizes the jet in an equilibrated state. The main equilibration mechanism is a homogenization of the lower-layer potential vorticity by deep eddies. The width of the homogenized zone is narrower for a larger slope and/or on the $\beta$ plane.

These results have the following implications to the Gulf Stream dynamics: 1) maximum of the meander amplitudes increase as the topographic slope relaxes in qualitative agreement with observed behavior of the Gulf Stream, 2) the phase locking of the meanders with deep eddies underneath at the nonlinear stage agrees qualitatively with the observed structure of large amplitude cyclonic troughs at the central array, and 3) the increase of the barotropic transport on the warm side of the jet and the generation of the recirculation on the cold side of the jet is consistent with observations in the Gulf Stream system downstream of Cape Hatteras.
\end{abstract}

\section{Introduction}

The path of the Gulf Stream is characterized by the presence of wavy perturbations, known as Gulf Stream meanders, that can grow and pinch off warm and cold core eddies downstream of Cape Hatteras. In the eddy formation region of the Gulf Stream system between Cape Hatteras and the Grand Banks, the northward transport of warm water from the Sargasso Sea and the southward transport of cold water from the continental slope occur through so-called Gulf Stream "rings" that are spun off from the stream after detachment from the continental coast. Due to significant impact of the Gulf Stream on the general circulation of the North Atlantic Ocean, in terms of both mass transport and eddy kinetic energy (e.g., Fofonov 1981), examination of the dy-

Corresponding author address: Dr. Isaac Ginis, Graduate School of Oceanography, University of Rhode Island, Narragansett Bay Campus, Narragansett, RI 02882.

E-mail: iginis@gso.uri.edu namics of the stream is clearly of more than local dynamical interest.

Many studies in past decades investigated physical mechanisms of meandering and eddy detachment in baroclinic jets such as the Gulf Stream. These studies have suggested that fluctuations in the Gulf Stream path are caused by baroclinic-barotropic instability processes that are influenced by the beta effect and bottom topography. Conventional linear stability theory has demonstrated some success in predicting the wavelengths and $e$-folding times of observed meanders. In particular, Holland and Haidvogel (1980) showed that temporal instabilities arising from a Gulf Stream-type jet are dominantly baroclinic with a wavelength of approximately $300 \mathrm{~km}$ and $e$-folding time near 6 days. Their results are in accord with both observations (Robinson et al. 1974) and the numerical simulations performed by Ikeda (1981).

Although conventional linear stability theory can predict reasonably well typical wavelengths and phase speeds of growing meanders, nonlinear effects dominate 



FIG. 1. Observational data at SYNOP experiment for dates shown [adopted from Watts et al. (1995)]. Deep pressure fields in decibars $(10 \mathrm{kPa}=1 \mathrm{dbar}$; $\mathrm{CI}=0.015 \mathrm{dbar})$ and isothermal surface $12^{\circ}$ in bold contours. Vectors indicate velocity observed at $3500 \mathrm{~m}$.

the evolution of large amplitude meanders and ring detachment. Using a two-layer quasigeostrophic (QG) model, Ikeda and Apel (1981) were the first to identify that nonlinear effects are responsible for the formation of coherent eddies upstream of meanders, which they named opposite vortices. The vertical structure of these vortices was found to be nearly barotropic with stronger signal in the lower layer. The name was given due to their direction of rotation, which was opposite to that of the nearby meanders. In the numerical simulations of the Gulf Stream by Robinson et al. (1988), in which a QG model was initialized from real data, such opposite vortices were also identified and named near-field circulation. In the numerical study by Spall and Robinson (1990) these opposite vortices were shown to have significant strength, on the order of $0.3 \mathrm{~m} \mathrm{~s}^{-1}$ at depths of thousands of meters in both QG and primitive equation simulations. These previous studies have shown that opposite vortices/near-field circulations play a crucial role in the final stages of meander growth and in the ring formation processes.

Because of nearly barotropic structure of opposite vortices they have weak temperature signals and therefore are not readily identifiable from hydrographic observations. Only a few observational evidences of these vortices exist. A possible relation between opposite vortices and warm outbreaks observed south of the Gulf Stream was suggested by Cornillon et al. (1986). During the Synoptic Ocean Prediction (SYNOP) observational program strong eddies were found in the vicinity of the Gulf Stream at a depth of $3500 \mathrm{~m}$ (Watts et al. 1995). These deep eddies are characterized by strong swirl speeds (up to $0.5 \mathrm{~m} \mathrm{~s}^{-1}$ ) and are long lived (typically lasting 6-9 weeks). The most pronounced deep cyclones during the SYNOP were found beneath large amplitude cyclonic troughs that routinely form in the Gulf Stream's path (Fig. 1). This phase locking of the upper meanders and deep eddies underneath differs from what can be expected during growth of baroclinic instability with associated vertical tilt (e.g., Eady 1949).

Previous studies also indicate that growing meanders and deep eddies, at the nonlinear stage of their development, are also able to modify the time-mean jet structure. This feedback of growing instabilities to the mean flow has been investigated using several approaches such as weakly nonlinear analysis (e.g., Pedlosky 1970), quasi-linear analysis (e.g., Phillips 1954; Shepherd 1983), and numerical simulations with fully nonlinear models (e.g., Rhines 1977; Ikeda 1981). For a symmetric jet, QG models describe symmetric cross-stream changes of the mean flow, while primitive equation simulations show a strong cross-stream asymmetry of the modified mean jet structure (e.g., Wood 1988; Boss and Tompson 1999).

Most often the growing instability is studied by constructing an initial flow with alongstream periodic meanders because it allows use of the normal mode method for linear analysis and simple periodic boundary conditions for numerical simulations. This approach is not strictly applicable to oceanographic currents, such as the Gulf Stream, where the meanders can grow in space downstream of Cape Hatteras. Generally, jet perturbations may arise from an initially localized in space pulse excitation, which develops as a wave packet growing and propagating downstream. A spatiotemporal analysis of pulse asymptotics provides an important conceptual distinction between the so-called absolute and convective instabilities (e.g., Farrel 1982; Pierrehumbert and Swanson 1995). In the former, the disturbance continues to grow in time at every point that has been reached by 
the traveling pulse; in particular, it continues to grow at the point of excitation. In the latter, the instability is carried along the stream so that, despite its constantly increasing amplitude, at any fixed point the disturbance eventually decreases; in particular, at the point of the excitation the effects of perturbation are eliminated after a finite time. Nonlinear evolution of such pulse excitation was studied numerically by Swanson and Pierrehumbert (1994) in a two-layer model, Straneo and Pinardi (1994) in a multilevel QG model, Bush et al. $(1995,1996)$ in the nonhydrostatic Boussinesq equations, and Flierl (1999) in a simplified two-layer hybrid model.

In most of the aforementioned studies the ocean bottom was assumed to be flat, and therefore the results have limited application to the Gulf Stream. Meanders and deep eddies in the Gulf Stream are expected to be strongly influenced by the bottom slope that changes downstream of Cape Hatteras toward Grand Banks from $\sim 0.005$ at $73^{\circ} \mathrm{W}$ to $\sim 0.002$ at $70^{\circ} \mathrm{W}$ (Kontoyiannis 1997). The role of bottom topography on baroclinic jets was investigated in a number of studies, mostly by linear stability analysis (e.g., Orlanski 1969; Blumsack and Gierasch 1972; de Szoeke 1975; Tang 1976; Mechoso 1980; Wright 1980a,b; Mechoso and Sinton 1981; Mysak et al. 1981; Luther and Bane 1985; Xue and Mellor 1993; Wang and Ikeda 1997; Kontoyannis 1997). These studies have clearly shown that a positive (same sense as isopycnal tilt) slope suppresses the meander growth rate compared to a flat bottom case. The theoretical results are supported by observations indicating that meanders do not grow upstream of the Cape Hatteras where the Gulf Stream flows over a steep continental slope. The role of weaker slopes downstream of Cape Hatteras on the meander evolution, especially at the nonlinear stage, remains unclear.

The aim of this paper is to study the effects of a topographic slope on nonlinear evolution of a spatially localized pulse in a Gulf Stream-type baroclinic jet. Specifically, we seek to answer the following questions: 1) How are Gulf Stream meanders downstream of Cape Hatteras modified over the continental slope? 2) How are the mean flow and deep eddies modified by bottom topography? 3) What are the effects of dynamical coupling between amplifying meanders and associated deep eddies?

In this study we employ a three-dimensional primitive equations model. A primitive equations model provides a significantly more faithful description of the eddy formation processes compared to a QG model, since the ageostrophic terms do contribute considerably, as shown by Wood (1988) and Spall and Robinson (1990). In our simulations an undisturbed baroclinic jet is prescribed with no initial deep flow. An additional barotropic component in the mean state, which may affect both the linear and nonlinear evolution of a baroclinically unstable jet (Killworth 1980; Simmons and Hoskins 1980;
Polavarapu and Peltier 1990; Thorncroft et al. 1993; Nakamura 1993), will be explored in a future paper.

The rest of the paper is organized as follows. The model and the experimental setup are described in section 2. The results of the numerical simulations are analyzed in section 3 . The comparison with linear analysis of the spatiotemporal instabilities is given in section 4 . Our principal conclusions and implications to the Gulf Stream dynamics are discussed in section 5 .

\section{Description of the model and experimental design}

The numerical model used in this study is the Princeton Ocean Model (POM) developed by Blumberg and Mellor (1987). This model is widely distributed to the academic community and industry and is run semioperationally as part of the Coastal Ocean Forecast System (COFS) at the National Centers for Environmental Prediction. The latest version of the model is described in detail by Mellor (1998) and therefore only briefly outlined here.

The POM is a three-dimensional primitive equation model with complete thermohaline dynamics. It has an ocean bottom following, sigma vertical coordinate system, and a free surface. Thus, it is capable of resolving the coastal areas adjacent to the deep ocean, including the continental shelf and slope. A second-order turbulence closure scheme (Mellor and Yamada 1982) is embedded in the model to provide mixing parameters. The momentum, heat, and turbulent kinetic energy equations are solved, and the prognostic variables of the free surface, potential temperature, salinity, and velocity are calculated. The horizontal diffusion terms are calculated using the scales of motion resolved by the model and the local deformation field (Smagorinsky 1963). The density is calculated using the modified UNESCO equation of state (Mellor 1998).

For this study the POM is configured as a zonal channel with two open boundaries on the inflow and outflow sides where special boundary conditions are applied to minimize boundary effects. The rectangular channel is $2400 \mathrm{~km}$ long and $1200 \mathrm{~km}$ wide. The average water depth is set to be $5000 \mathrm{~km}$. The horizontal resolution is $10 \mathrm{~km} \times 10 \mathrm{~km}$, which is $1 / 3$ of the mean baroclinic Rossby radius and $1 / 30$ of the dominant meander wavelength. There are 20 vertical $\sigma$ levels with higher resolution in the upper ocean.

A Gulf Stream-type, baroclinic jet in the mean state is initialized as a potential vorticity (PV) front because the stability properties of a jet are strongly linked to its PV distribution, which also has an important property of Lagrangian conservation in inviscid flows. Potential vorticity front initialization has been widely used in reduced gravity and two-layer models for analytical and numerical studies of the Gulf Stream (e.g., Stommel 1965; Pratt and Stern 1986; Sutyrin and Yushina 1989; Meacham 1991; Boss et al. 1996; Flierl 1999). In a two- 
layer model the PV front representation in the upper layer is based on observations of the hydrographic and velocity structure of the Gulf Stream after its separation from the U.S. coastal line near Cape Hatteras (e.g., Halkin and Rossby 1985; Leaman et al. 1989). It characterizes the Gulf Stream as a front separating two regions of differing PV structures, the Sargasso Sea to the south and the slope water to the north. The PV structure in the lower layer is defined mostly by the interface depth and topography.

A two-layer PV representation is clearly an oversimplification of the real Gulf Stream structure. Since water parcels move along isopycnals rather then along isobars, the essential PV features are better retained and emphasized in a multilayer representation that we use here. A Gulf Stream-type jet is represented by PV gradients in five layers (see appendix). The chosen five-layer structure is interpolated onto the POM $\sigma$ levels. Figure 2 shows the comparison of geostrophic velocity and temperature fields in the model with the observations of Halkin and Rossby (1985) at $73^{\circ} \mathrm{W}$. Although the main PV front is symmetric in the upper layer, the jet structure in the model is asymmetric due to large difference in the upper layer depth to the south and to the north of the jet, in qualitative agreement with the observed Gulf Stream structure.

\section{Simulation results}

In this section we discuss a set of numerical experiments with the same initial density field and boundary conditions but for various bottom slopes and $\beta$ effects. In the Gulf Stream region downstream from Cape Hatteras, the bottom slope relaxes from $\sim 0.005$ at $73^{\circ} \mathrm{W}$ to $\sim 0.002$ at $70^{\circ} \mathrm{W}$. In our experiments we considered either a weak uniform slope $(0.002)$ or a flat bottom and either the $f$ plane or the $\beta$ plane $\left(\beta=2 \times 10^{-11} \mathrm{~m}^{-1}\right.$ $\left.\mathrm{s}^{-1}\right)$. Note that initial geostrophically balanced mean flow with no motion in the lower layer does not depend on the bottom slope and only slightly depends on the $\beta$ effect.

A small amplitude, vertically uniform perturbation of the jet stream position, with a Gaussian alongstream profile centered at $x=0$, was introduced at time $t=$ 0 , and the subsequent evolution was calculated for 60 days. In general, the introduction of a small perturbation induced the growth of jet meanders that amplified as they propagated downstream. Most of the graphical representations of the model fields in the following subsections will focus on subregions of the computational domain for clarity.

\section{a. Flat bottom}

Evolution of jet meanders and deep circulations in the flat bottom case on the $f$ plane is shown in the left panel of Fig. 3. The temperature in the upper layer at a depth $250 \mathrm{~m}$ is superimposed by the streamfunction

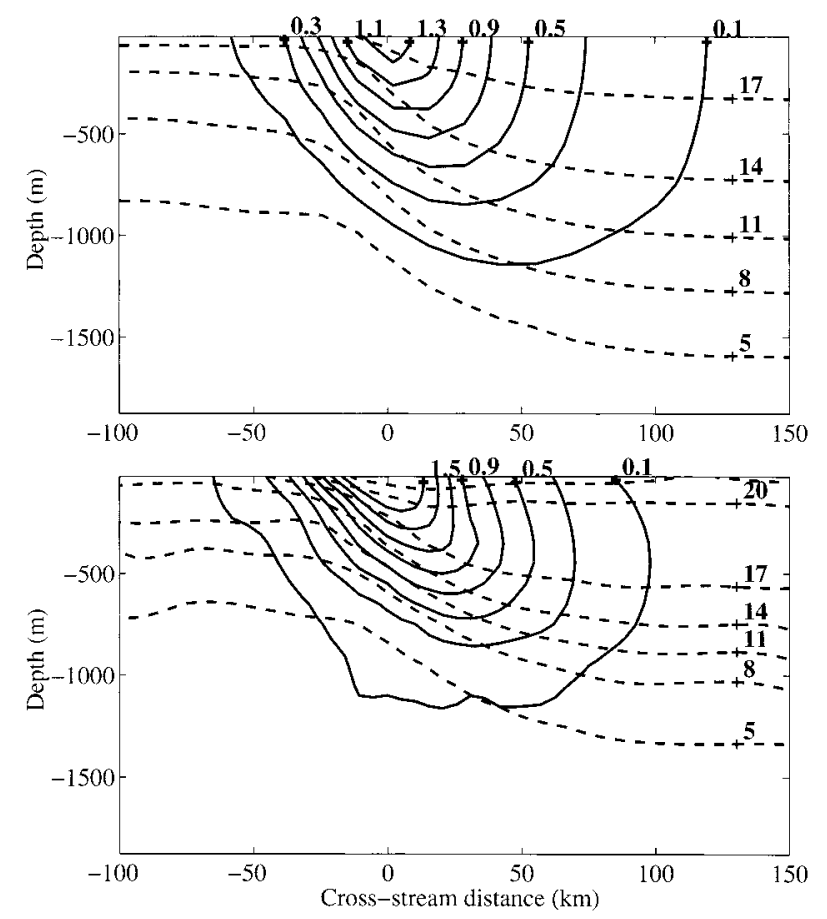

FIG. 2. Two-dimensional mean state temperature and baroclinic velocity observed in the Gulf Stream at $73^{\circ} \mathrm{W}$ (Halkin and Rossby 1985 ) with substracted velocity at $1800 \mathrm{~m}$ (lower panel) and given by the PV-gradient model as described in the text. CI $=0.2 \mathrm{~m} \mathrm{~s}^{-1}$.

in the lower layer calculated by inverting vorticity at a deep level $2500 \mathrm{~m}$. The upper-layer temperature evolution shows that the initially specified small meander grows and propagates downstream and takes the form of a wave packet consisting of growing meanders accompanied by cyclones and anticyclones in the lower layer, which we call the deep eddies. The number and intensity of the deep eddies increase being coupled with the meander growth by the baroclinic instability mechanism.

The perturbation in the lower layer can be characterized by the deep PV anomalies (PVA) as

$$
\text { PVA }=Q-Q_{\text {init }}, \quad Q=\frac{f+\xi}{H-Z},
$$

where $\xi$ is depth-averaged vorticity in the layer below the isopycnal surface $\sigma_{t}=27.76$ where the motion is almost independent on depth (corresponding to the streamfunction presented in Fig. 3), $H$ is the ocean depth, and $Z$ is the thermocline depth corresponding to the isopycnal surface $\sigma_{t}=27.76$. The thermocline depth is characterized by the temperature in the upper layer, which is also shown in Fig. 3.

As pointed out by Flierl (1999), with an $f$-plane twolayer model, the flow associated with deep PVA is predominantly barotropic. In order to assess the structure and intensity of flows associated with deep PVA in our model, we calculated the upper and lower layer flows assuming horizontally homogenious stratification above 


\section{FLAT BOTTOM}
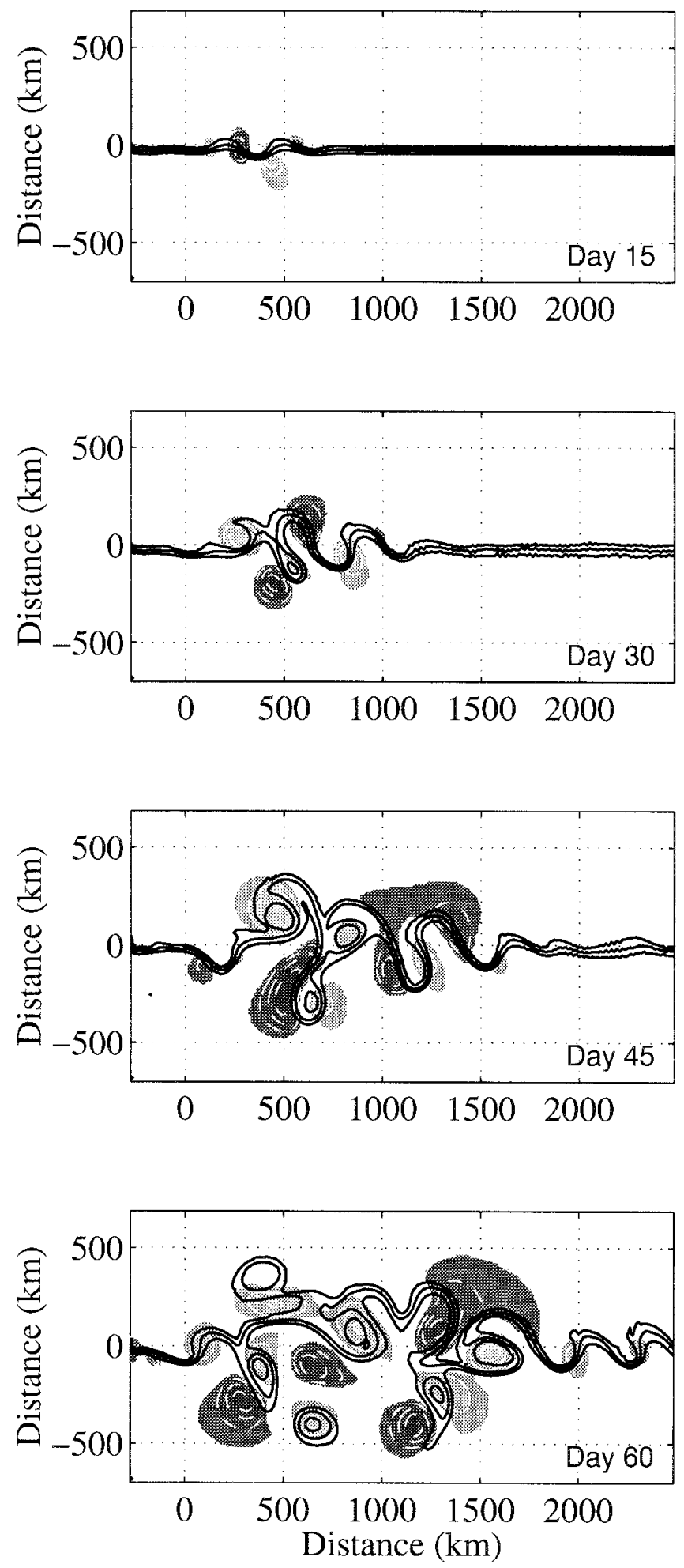

SLOPING BOTTOM
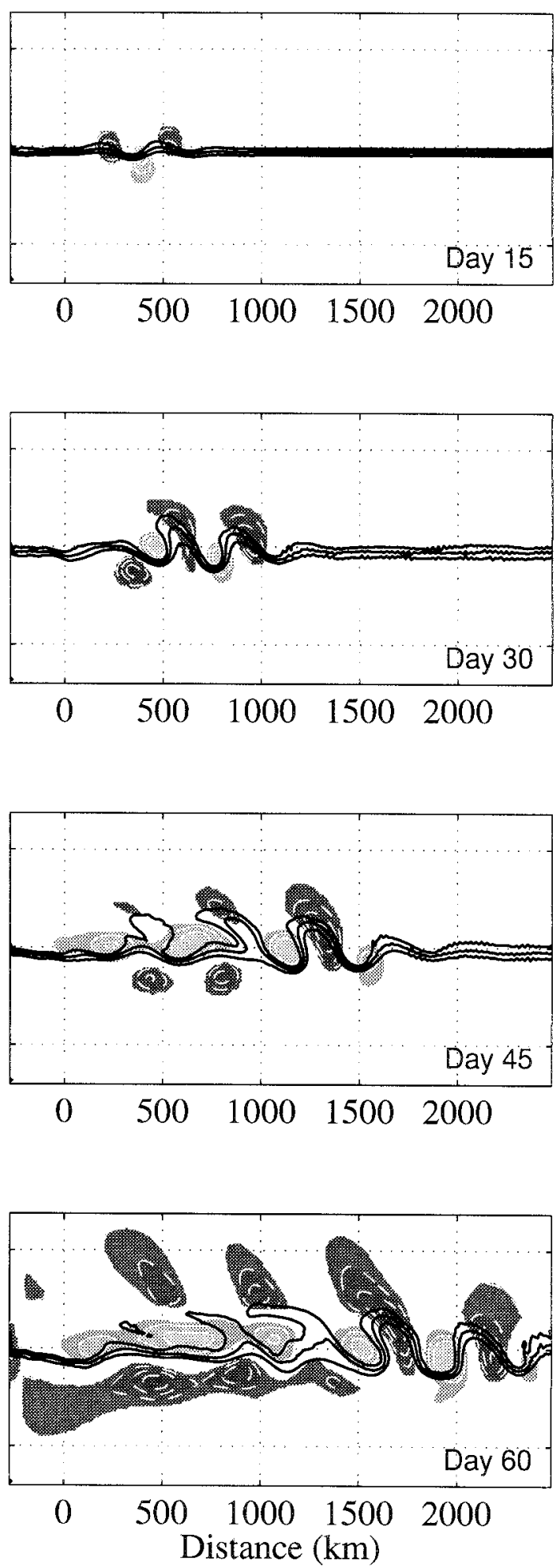

FIG. 3. Temperature at a depth $275 \mathrm{~m}$ (solid lines, $\mathrm{CI}=2^{\circ}$ ) superimposed by the solenoidal streamfunction at a depth $2500 \mathrm{~m}$ (dashed white lines) at subsequent times $15,30,45$, and 60 days on the $f$ plane for the flat bottom (left panel) and sloping bottom (right panel). Dark and light gray correspond to anticyclonic and cyclonic vorticity in the lower layer. 
the lower layer. Figure 4 shows that the upper layer flow has similar structure, although it is less intense than in the lower layer because of stratification in the thermocline. The structure of deep eddies is dominated by lower-layer flow associated with the deep PVA, as seen by comparing Figs. 3 and 4. Therefore, the lower-layer streamfunctions, shown in Fig. 3 and Fig. 8, characterize also the upper flow associated with deep PVA that provides an important feedback for the meander growth.

During the first 15 days, the centers of the deep eddies are located between the meander crests and troughs along the initial basic state jet maximum (day 15 in Fig. 3 and day 20 in Fig. 4a). This vertical phase shift is associated with the linear stage of meander growth and is consistent with baroclinic instability theory (e.g., Eady 1949) and other numerical studies (e.g., Rhines 1977). At this stage, the upper-layer flow associated with the deep PVA is much weaker than the jet velocity. In about a month after the beginning of integration the centers of deep eddies are shifted away from the jet axis due to the nonlinear effects (day 30 in Fig. 3 and Fig. 4b). Now the upper-layer flow associated with the deep PVA forms a so-called near-field circulation, following the terminology introduced by Robinson et al. (1988). The cyclonic circulations that arise adjacent to the warm anticyclonic meanders and, similarly, the anticyclonic circulations that arise adjacent to the cold cyclonic meanders are clearly seen at days 30 and 45 (Fig. 3 and Fig. 4b). These features play an important role in the ring cutoff process and in the life cycle of detached rings seen at day 60 in Fig. 3, as discussed in details by Bush et al. (1996).

To examine further the deep flow structure in terms of potential vorticity transformation, we consider the evolution of $Q$ itself. We should note that in a numerical model, PV in fluid particles at deep levels is conserved only to the extent that the numerical dissipation does not contribute significantly to the dynamics. The transformation of the lower-layer PV is shown in the lower panel of Fig. 5 at day 40 together with its meridional profile zonally averaged over the packet zone. In this flat bottom case the PV transformation is similar to that described by Bush et al. (1995). In the cyclonic nearfield circulations associated with warm meanders, the cyclonic vorticity increases, as does the thickness of the column, because of the raised thermocline. This change would imply through the conservation of PV that water with a higher value of PV must be advected into the column. Conversely, the anticyclonic near-field circulations associated with cold meanders are characterized by increasing anticyclonic vorticity and decreasing column thickness due to the depressed thermocline. Conservation of PV demands that water with a lower value of PV is advected into the column. In the deep layer under consideration PV is lower on the cold side of the jet and higher on the warm side of the jet (opposite to what is in the upper layer). This configuration would imply that there is a cross-stream transport of high PV water from the warm side of the jet into the cyclonic near-field circulations on the cold side of the jet. Similarly, low PV water from the cold side of the jet flows into the anticyclonic near-field circulations on the warm side of the jet. These effects are clearly seen in Fig. 5. Note that in the case of flat bottom the deep eddies are able to only slightly alter the cross-stream zonally averaged PV gradient behind the packet peak, as seen in the right upper panel of Fig. 5 .

In order to quantify the growth of the deep eddy packet we consider the evolution of the cross-stream velocity. This velocity is zero in the unperturbed mean state; therefore, any growing disturbance has a clear signature in this dynamical field at all depths. A typical vertical section of the cross-stream velocity along the position of the velocity maximum in the initial state after 20 days is shown in Fig. 6. Vertical tilts upstream with height (leading the perturbation overhead) in the upper $1000 \mathrm{~m}$ are clearly seen. This provides the necessary condition to the release of available potential energy during baroclinic instability (Eady 1949). Below about $1000 \mathrm{~m}$ the velocity is nearly barotropic, and its structure is nearly the same at all depths.

We now consider the evolution of the cross-stream velocity along the initial jet velocity maximum at the depth $2500 \mathrm{~m}$. Figure 7 shows the time series of the maximum absolute value of the cross-stream velocity in this case (solid line). After a transient period $(t<$ $\left.t_{1}\right)$, the perturbation undergoes an exponential growth $\left(t_{1}<t<t_{2}\right)$ characterized by the almost linear slope in Fig. 7. In this case, $t_{1} \simeq 10$ days and $t_{2} \simeq 20$ days when the cross-stream velocity increases from 0.1 up to $0.35 \mathrm{~m} \mathrm{~s}^{-1}$. Thereafter, the nonlinear effects become pronounced, and during the next 20 days the deep crossstream velocity gradually increases and oscillates around the value of about $0.5 \mathrm{~m} \mathrm{~s}^{-1}$. In the last 20 days, the maximum cross-stream velocity increases up to 0.65 $\mathrm{m} \mathrm{s}^{-1}$ when rings are formed from the jet meanders (day 60 in Fig. 3).

\section{b. Sloping bottom}

In the presence of a weak topographic slope of 0.002 the initial development of the meanders and associated deep eddies is nearly the same as in the flat bottom case during the first 15 days (right panels in Fig. 3). As can be seen in Fig. 7 (dashed line), the transient period is also nearly the same $\left(t_{1} \simeq 10\right.$ days $)$, and the stage of exponential growth ends at the same time ( $t_{2} \simeq 20$ days). The growth rate is only slightly less, as characterized by the slope of dashed line between $t_{1}$ and $t_{2}$.

The most essential difference from the flat bottom case can be seen at the stage when the nonlinear effects come to play $\left(t>t_{2}\right)$. As seen from Fig. 7, the maximum cross-stream velocity of the deep eddies saturates at a lower amplitude of about $0.35 \mathrm{~m} \mathrm{~s}^{-1}$ and gradually decreases after day 37 down to $0.3 \mathrm{~m} \mathrm{~s}^{-1}$. At the nonlinear stage, the topographic slope prevents the deep eddies 

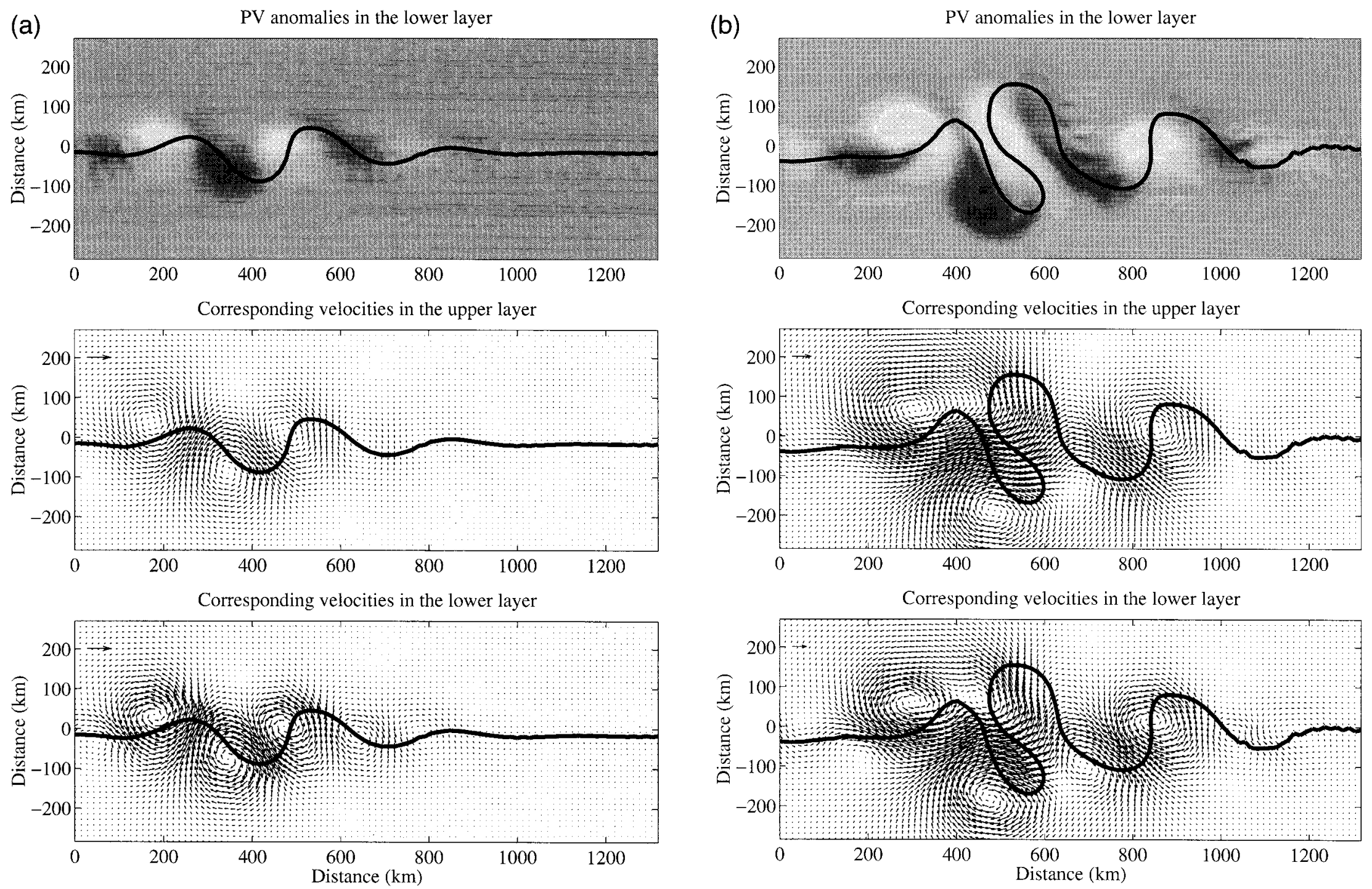

FIG. 4. Potential vorticity anomalies (upper panel) in the lower layer and associated velocities in the upper layer (middle panel) at depth $250 \mathrm{~m}$ and in the lower layer (lower panel) in the $f$ plane and flat bottom experiments calculated assuming horizontally homogenious stratification above the lower layer: (a) at day 20 and (b) at day 30 . Bold lines show the characteristic isoterm of $15^{\circ} \mathrm{C}$. Velocity scale of $0.5 \mathrm{~m} \mathrm{~s}^{-1}$ is shown by arrows. 


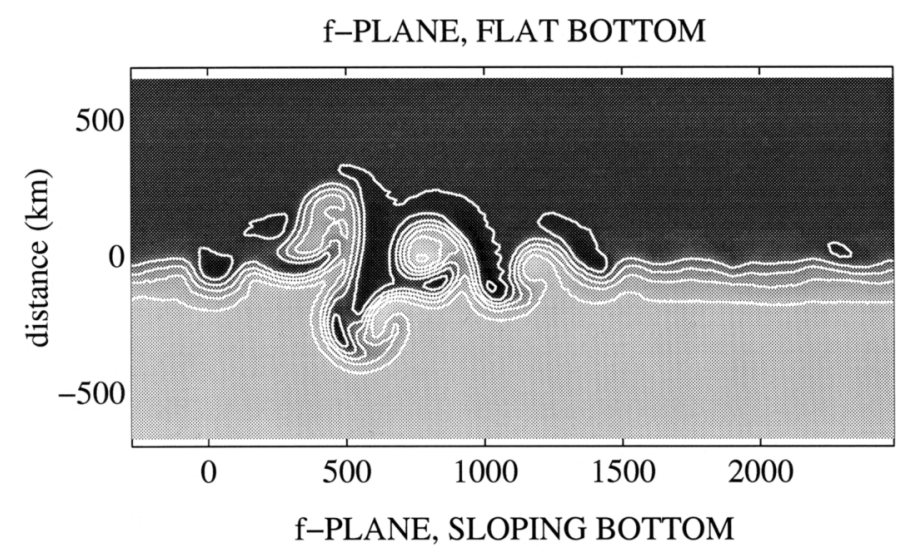

\section{f-PLANE, FLAT BOTTOM}

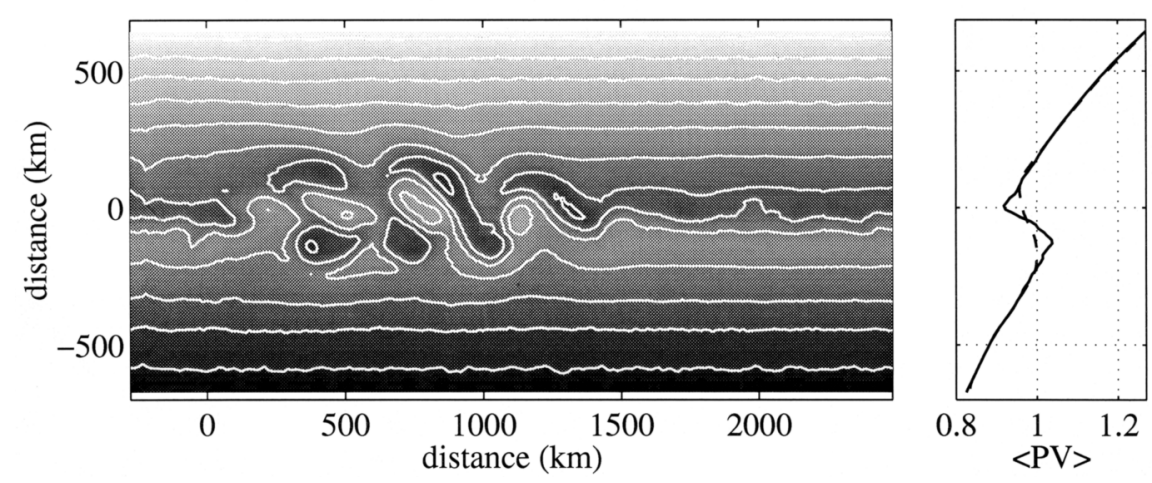

FIG. 5. Lower-layer PV at day 40 for the flat bottom (upper panel) and sloping bottom (lower panel) on the $f$ plane. The right plots show zonally averaged deep PV profiles behind the wave packet zone at $t=0$ (solid line) and day 40 (dashed). Lower layer PV is normalized by its mean value in the domain.

from large cross-stream displacement, which was important in inducing the near-field circulation in the upper layer in the flat bottom case (cf. right and left panels in Fig. 3). Instead, we see the phase displacement of deep eddies and corresponding upper layer "nearby circu-

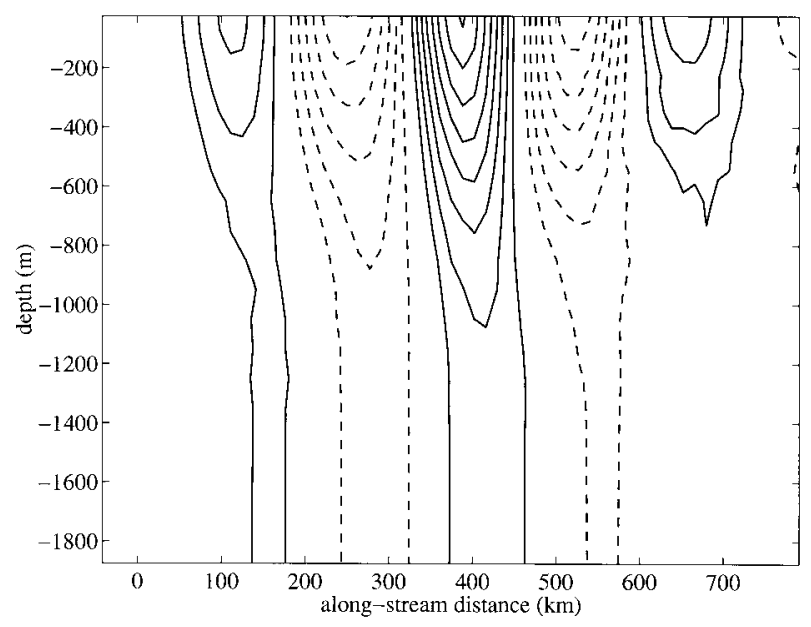

FIG. 6. Vertical section of the cross-stream velocity along the basic state jet maximum at day $20 . \mathrm{CI}=0.1 \mathrm{~m} \mathrm{~s}^{-1}$. lation" associated with deep PVA in the direction of the upper-layer troughs/crests. This phase locking of the meanders with the deep eddies underneath results in saturation of the packet peak amplitude. It is the main physical mechanism of the packet peak saturation in the presence of a topographic slope. No ring pinching off occurs in this case, as seen in the right panel in Fig. 3. We should note that the positions of the deep cyclones beneath the meander troughs agree qualitatively with the observational data at the SYNOP central array shown in Fig. 1.

Another important new feature found in the slope bottom case is the formation of a nearly zonal flow behind the packet peak. Unlike in the flat bottom case, the meander amplitudes decay behind the packet peak while like-sign deep eddies merge. As a result, an additional circulation is formed that intensifies the jet. Furthermore, new recirculations are generated to the north and south of the jet (see day 60 at Fig. 3) in a manner similar to what was found in the two-layer simulations for a flat bottom on the $\beta$ plane (e.g., Rhines 1977; Swanson and Pierrehumbert 1994). We can thus conclude that in the presence of a slope a mature wave packet leaves behind an equilibrated state with a modified mean jet structure and surrounded recirculations. 


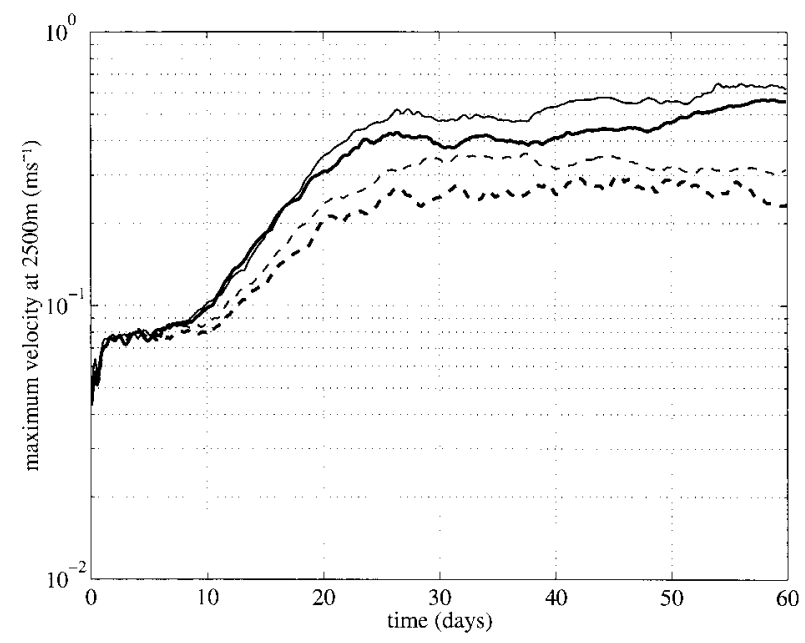

FIG. 7. Time evolution of maximum cross-stream velocity at depth $2500 \mathrm{~m}$ on the $\beta$ plane for the flat bottom (solid bold line) and sloping bottom (dashed bold line) and on the $f$ plane for the flat bottom (solid line) and sloping bottom (dashed line).

In the presence of the slope, PV transformation in the deep layer differs significantly from the flat bottom case, as seen in Fig. 5. The difference is due to the fact that the deep-layer thickness, $H-Z$, has extrema not far from the jet maximum where the thermocline slope equals the bottom slope. This restricts growth of the near-field circulations due to the cross-stream advection of PV, as described in the flat bottom case. For the sloping bottom, the PV gradient zone favorable for the baroclinic instability is constrained by initial extrema seen at the right lower panel of Fig. 5. As a result, the zonally averaged PV gradient in the lower layer is almost eliminated in about $250 \mathrm{~km}$ zone by the horizontal mixing induced by the deep eddies. As can be inferred from the lower left panel at Fig. 5, the deep PV redistribution is predominantly advective, although viscous dissipation also contributes to PV modification in fluid parcels with time. Merging like-sign deep eddies and formation of nearly zonal deep circulation indicate enhanced mixing and actual PV conversion within water parcels.

In summary, the main jet equilibration mechanism over a sloping bottom is a homogenization of the deep potential vorticity by deep eddies behind a moving wave packet peak. It should be noted that PV in the upper levels (not shown) does not homogenize; the homogenization in the deep interior alone is sufficient to stabilize the jet.

\section{c. Experiments on the $\beta$ plane}

In order to investigate the role of the $\beta$ effect on meander and deep eddy evolution in a baroclinic jet, we conducted the same experiments as discussed above but on the $\beta$ plane. It is found that the growth rates of the deep eddies in the flat and sloping bottom cases are only about $15 \%$ smaller than the corresponding rates on the $f$ plane (Fig. 7). While the stage of exponential growth ends at approximately the same time $\left(t_{2} \simeq 20\right.$ days), the deep cross-stream velocity saturates at smaller values by about $20 \%$ than on the $f$ plane.

Comparing Figs. 3 and 8, we see that at the nonlinear stage, the difference between the flat and sloping bottom cases on the $f$ plane is more pronounced than on the $\beta$ plane. For the flat bottom on the $\beta$ plane, the near-field circulation induced by the deep PVA is weaker, the detachment of rings is less efficient, and the rings are not able to propagate far from the jet, as seen in the left panel of Fig. 8.

In the slope bottom case on the $f$ plane, the deep eddies occupy a wider zone than on the $\beta$ plane (cf. right panels of Figs. 3 and 8) due to a wider zone favorable for baroclinic instability (cf. lower right panels of Figs. 5 and 9). Correspondingly, the deep zonal flow behind the packet peak is wider and more intense on the $f$ plane than on the $\beta$ plane (cf. lower and upper panels of Fig. 10). Note a strong asymmetry of zonally averaged deep flow; it accelerates the jet mostly at the warm side and generates a recirculation that is more pronounced at the cold side.

The width of the zone between the PV extrema in the lower layer can be defined by the locations where the thermocline slope is equal to the sum of the topographic slope $S$ and the ratio $S_{b}$

$$
S_{b}=\frac{\beta(H-Z)}{f} .
$$

Baroclinic instability occurs when $S+S_{b}$ is less than the maximum thermocline slope, $S_{\max } \simeq 0.0075$ in all cases. The supercriticality of the flow can be characterized by

$$
\gamma=1-\frac{S+S_{b}}{S_{\max }} .
$$

The cases of maximum supercriticality $\gamma=1$ for the flat bottom and $\gamma=0.73$ for the slope 0.002 were described in the previous section for the $f$ plane. In our experiments $S_{b} \simeq 0.001$, corresponding to $\gamma=0.87$ for the flat bottom and $\gamma=0.6$ for the slope bottom on the $\beta$ plane.

This comparison between the $\beta$ plane and $f$ plane indicates that, for such a strong and narrow jet as the Gulf Stream, the $\beta$ effect does not play as essential role as it does for atmospheric jets. For example, results of Swanson and Pierrehumbert (1994) were obtained with a two-layer atmospheric model over a flat bottom for the supercriticality $\gamma=0.6$ defined by the $\beta$ effect alone. In summary, we should emphasize that in spite of the similarities of the wave packet evolutions on the $f$ plane and $\beta$ plane, it is important to take into account the $\beta$ effect for more realistic simulations of Gulf Stream meanders (see also Polovarapu and Peltier 1990). 
FLAT BOTTOM, BETA PLANE


SLOPING BOTTOM, BETA PLANE
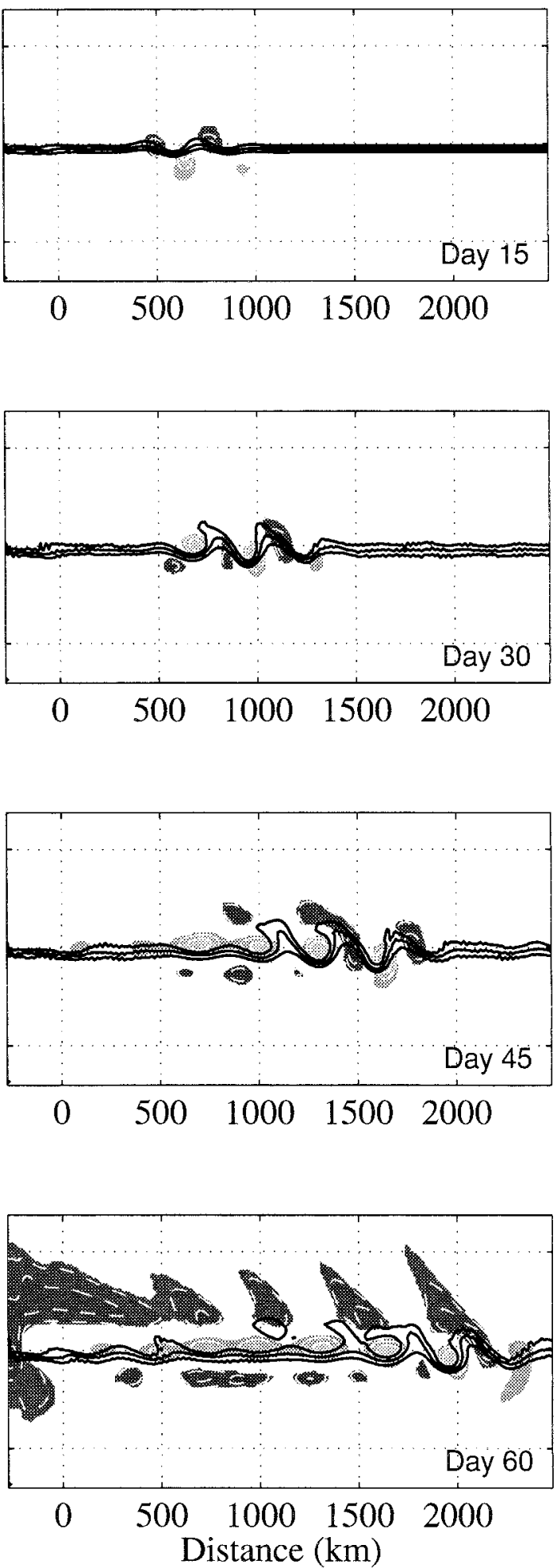

FIG. 8. Temperature at depth $275 \mathrm{~m}$ (solid lines, $\mathrm{CI}=2^{\circ}$ ) superimposed by the solenoidal streamfunction (dashed white lines) at depth $2500 \mathrm{~m}$ at subsequent times 15, 30, 45, and 60 days on the $\beta$ plane for the flat bottom (left panel) and slope bottom (right panel). Dark and light gray corresponds to anticyclonic and cyclonic vorticity in the lower layer. 

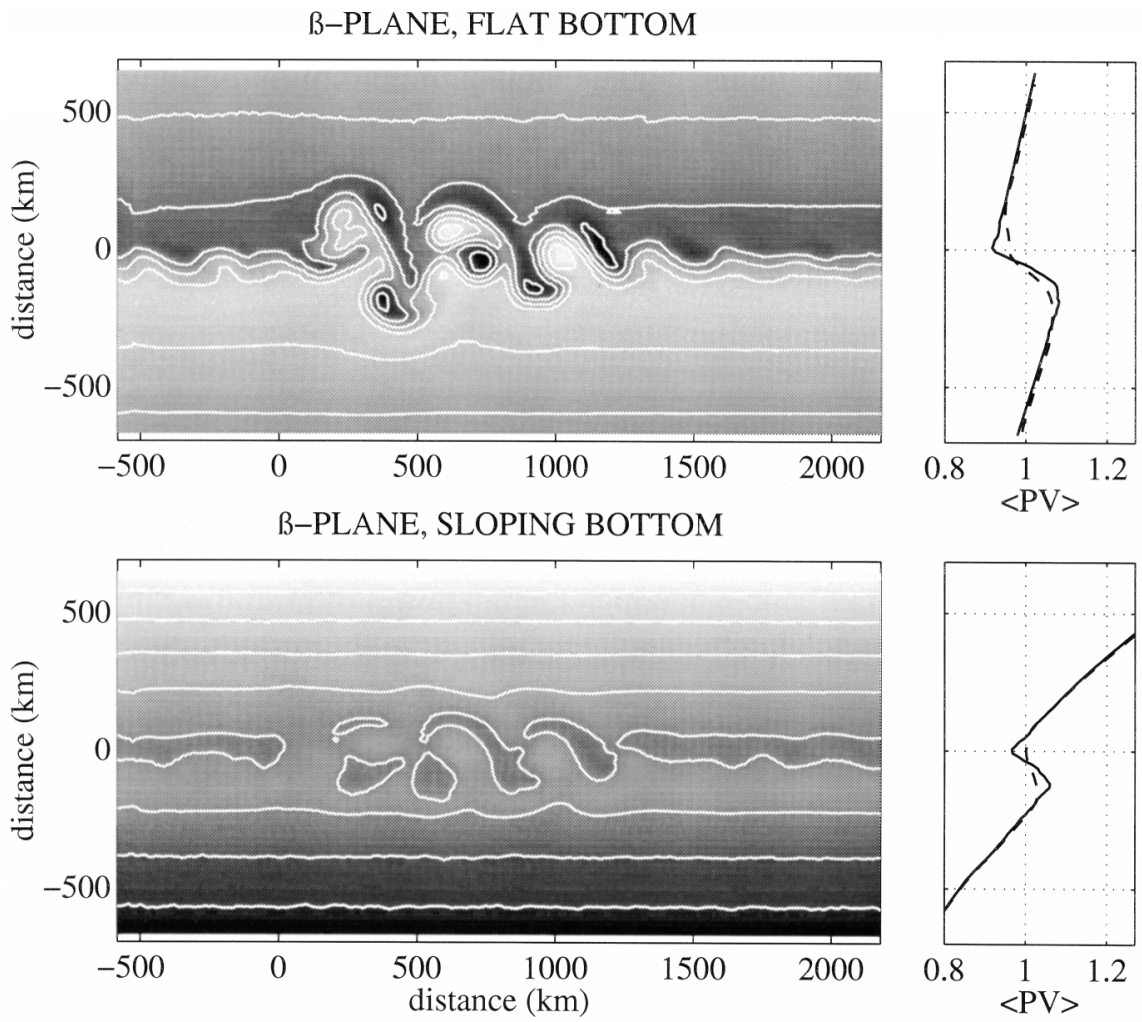

FIG. 9. Lower layer PV at day 40 for the flat bottom (upper panel) and sloping bottom (lower panel) on the $\beta$ plane. The right plots show zonally averaged deep PV profiles behind the wave packet zone at $t=0$ (solid line) and day 40 (dashed). Lower layer PV is normalized by its mean value in the domain.

\section{Properties of the wave packet}

In this section we analyze the properties of the wave packet in greater detail by invoking the pulse asymptotics theory. This theory provides a useful guidance for describing properties of the wave packet evolutionin particular, for distinguishing between absolute and convective instabilities.

We first briefly outline the linear stability analysis of the spatiotemporal development of localized perturbations to a baroclinic background flow. Perturbations of velocity and temperature to their values in the mean background state can be expressed in normal mode form as

$$
\operatorname{Re}[\hat{\Psi}(y, z) \exp (-i \sigma t)]
$$

where $\sigma=\omega-k x / t,(x, y, z)$ are alongstream, crossstream, and vertical coordinates, correspondingly. In general, both frequency $\omega$ and wavenumber $k$ can be complex. Upon substituting into the governing equations of motion and linearizing about the background state, one arrives at an eigenvalue problem with the eigenfunction solutions $\hat{\Psi}$ to exist only if $k$ and $\omega$ are constrained to satisfy a dispersion relation. Generally, the eigenvalue problem is solved numerically either for temporal modes of spatially periodic perturbations or for spatiotemporal modes of wave packets.
In the temporal formulation of instability problems that consider the growth in situ of spatially periodic perturbations, a real wavenumber $k$ is prescribed and the corresponding complex frequency $\omega(k)$ is sought. If the flow is unstable, the temporal normal modes grow exponentially for some wavenumbers and decay for other wavenumbers. The growth rate is given by the imaginary part $\operatorname{Im} \omega=\omega_{i}(k)$, while the real part of $\omega$ provides the phase speed $C_{\text {phi }}(k)=\operatorname{Re} \omega / k$. The maximum growth rate $\omega_{i}\left(k_{\max }\right)$ gives the wavelength $\lambda_{\max }=2 \pi / k_{\max }$ of the fastest growing temporal mode. The temporal modes for Gulf Stream type jets are found to have $\lambda_{\max } \sim 250$ $300 \mathrm{~km}$ and $\omega_{i}\left(k_{\max }\right) \sim 0.15-0.25$ day $^{-1}$ [e.g., see Kontoyanis (1997) and references therein].

Considering only the temporal modes is not sufficient to properly categorize the spatiotemporal development of perturbations arising from a spatially localized excitation, as they provide the growth rate only for real wavenumbers. Any localized pulse developing along the streamwise direction is transformed into a wave packet of spatiotemporal modes that grow exponentially along some rays $x / t=$ const but decay along other rays. For the pulse asymptotics at $t \rightarrow \infty$, the amplitude of the wave packet along the ray $x / t=$ const behaves as

$$
A(x, t) \infty t^{-1 / 2} e^{\sigma_{i} t}
$$





FIG. 10. Alongstream velocity $\left(\mathrm{m} \mathrm{s}^{-1}\right)$ at day 60 at depth $2500 \mathrm{~m}$ (left panels) and cross-stream profiles of the alongstream velocity zonally averaged behind the packet peak (dashed lines in right panels) for the sloping bottom cases on the $\beta$ plane (upper panels) and the $f$ plane (lower panels). Initial state is shown by solid lines.

(Farrel 1982; Huerre and Monkewitz 1990). In order to calculate the growth rate of the pulse, $\sigma_{i}=\omega_{i}-k_{i} x / t$, the eigenvalue problem has to be solved considering both $k=k_{r}+\iota k_{\iota}$ and $\omega=\omega_{r}+\iota \omega_{i}$ as complex quantities for given real group velocity $\partial \omega / \partial k=x / t$. The asymptotics (5) allow one to estimate $\sigma_{i}(x / t)$ in a numerical model during the stage of linear growth from the amplitude of the wave packet envelope as follows:

$$
\sigma_{i}\left(\frac{x}{t}\right) \sim \frac{d}{d t} \ln \left[t^{1 / 2} A\right], \quad \frac{x}{t}=\text { const, } \quad t \rightarrow \infty .
$$

It should be borne in mind that these linear asymptotics are valid only after an unspecified long time has elapsed since the original perturbation; it is possible that for some initial conditions the entire development to nonlinear equilibration of the system being modeled may take place before these results obtain validity. However, these asymptotics are found to be useful to interpret the results of our numerical experiments.

Generally, the structure of amplifying baroclinic wave packets can be characterized by three distinguished rays. Ray $(x / t)_{m}$ for which $\sigma_{i}$ takes on its maximum value defines the position of the peak of the wave packet. Its structure near the peak is dominated by the most unstable temporal normal mode with $k_{i}=0$, so that $\sigma_{i \text { max }}$ $=\omega_{i}\left(k_{\max }\right)$. Upstream of the peak, $k_{i}$ is negative, while downstream of the peak, $k_{i}$ is positive; hence, during its linear growth the packet envelope decays exponentially with distance from the peak. Ray $(x / t)_{-}$for which $\sigma_{i}$ first becomes positive locates the trailing edge of the wave packet. Finally, ray $(x / t)_{+}$for which $\sigma_{i}$ returns to zero defines the leading edge where phase lines propagate slower than the envelope of the packet so individual highs and lows appear to move toward the rear when viewed in the frame moving with the leading edge speed.

In a fully nonlinear numerical solution the exponential growth becomes compensated by the nonlinear terms, and the central part of a wave packet saturates. Although the linear theory cannot describe the saturation of a wave packet at the nonlinear stage, the upstream and downstream development of the disturbance near the leading and trailing edges of the packet typically obeys the linear wave theory throughout the nonlinear evolution of the central part of the wave packet (e.g., Swanson and Pierrehumbert 1994). 


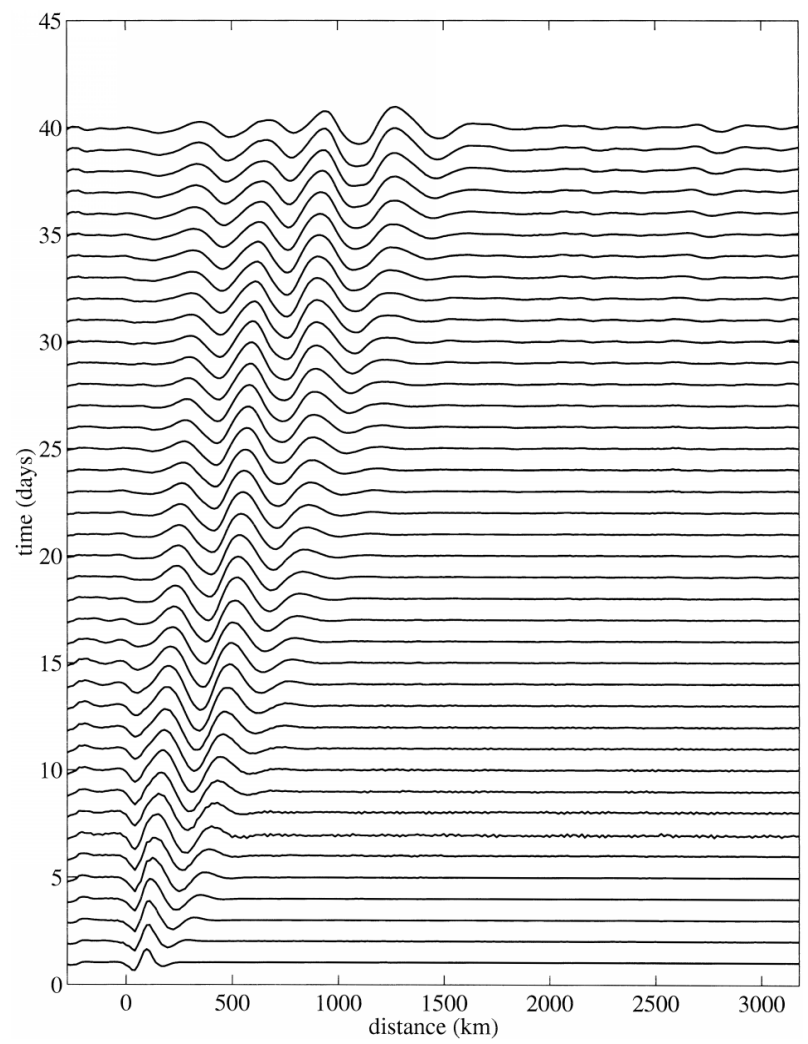

FIG. 11. Time series of the cross-stream velocity in the deep eddy packet along the initial basic state jet maximum, with amplitude normalized to the maximum at each day up to 40 days for the flat bottom on the $\beta$ plane.

The deep-eddy packet propagation and its spreading is shown in Fig. 11 as time sequences of the cross-stream velocities with amplitude normalized by its maximum at each day. We see that the phase lines connecting the velocity extrema at subsequent times indeed propagate more slowly than the envelope of the packet, so individual highs and lows appear to move toward the rear when viewed in the frame moving with the leading edge speed. It is consistent with the pulse asymptotics analysis of Swanson and Pierrehumbert (1994).

In order to determine more clearly the spatiotemporal properties of the deep flow development, a time series of the alongjet distribution of absolute value of the cross-stream velocity is plotted as a function of $(x / t)$ in Fig. 12. The amplitude $A$ of the packet envelope characterizes the spatiotemporal growth rate $\sigma_{i}$ during the exponential growth stage according to (5). Using asymptotics (6), we obtain $\sigma_{i \text {, max }} \simeq 0.15$ day $^{-1}$ for this case. At the end of this stage $t=t_{2} \simeq 20$ days; thus the nondimensional time $t_{2} \sigma_{i \text { max }} \simeq 3$ cannot be considered large enough to expect accurate validity of the asymptotics. However, we clearly see a tendency for the envelope to be confined between the rays $x / t \sim 0.5 \mathrm{~m}$ $\mathrm{s}^{-1}$ and $x / t \sim 0$, which provide estimates for the leading and trailing edges. The maximum of the envelope am- plitude is observed along the ray $(x / t)_{m} \simeq 0.2-0.25$ $\mathrm{m} \mathrm{s}^{-1}$, which characterizes the group velocity of the packet peak.

To better show an asymmetry in the packet structure, a reference function

$$
\frac{A}{A_{m}}=1-\left[1-\frac{(x / t)}{(x / t)_{c}}\right]^{1.5},
$$

symmetric relative to the ray $(x / t)_{c}=0.25 \mathrm{~m} \mathrm{~s}^{-1}$, is plotted by the dashed line in Fig. 12. It is apparent that at the end of the linear stage $\left(t=t_{2}\right)$ the frontal part of the packet has slightly smaller slope than the rear part. At the nolinear stage $\left(t>t_{2}\right)$, the packet peak becomes shifted toward the leading edge. However, the propagation of the leading and trailing edges seems unaffected by the nonlinear effects.

In the case of sloping bottom $(\gamma=0.6)$, the spatiotemporal development of baroclinic instability at the linear stage $\left(t<t_{2}\right)$ is similar to the flat bottom case $(\gamma=0.87)$ (cf. Fig. 12a and Fig. 12b). The disturbance remains confined by the leading and trailing edges, propagating with the nearly same speed as at the stage of exponential growth (Fig. 12b). However, at later times ( $t>30$ days), the peak of the wave packet no longer travels with the group speed of the linearly most unstable mode; it propagates faster, dominated by the modes at the leading edge of the packet as seen in upper plots in Fig. 12b. These features of the packet evolution are in a qualitative agreement with the results of Swanson and Pierrehumbert (1994) obtained with a two-layer atmospheric model over a flat bottom for $\gamma=0.6$. Our results also demonstrate that the baroclinic instability in all cases is predominantly convective as there is no noticeable upstream propagation of the perturbations.

\section{Discussion and conclusions}

In this paper, we investigated the role of a topographic slope and the $\beta$ effect on the spatiotemporal evolution of a localized small amplitude meander in a Gulf Stream-type baroclinically unstable jet. We initialized an unperturbed jet structure from a five-layer PV-gradient model suggested by Logoutov et al. (2001) with quiscent bottom layer over a positive (same sense as isopycnal tilt) cross-stream continental slope. A series of numerical experiments was conducted with the same initial conditions over sloping and flat bottoms on the $\beta$ plane and the $f$ plane using a three-dimensional primitive equation model.

An initially localized meander evolves into a wave packet and generates deep eddies that provide a positive feedback for the meander growth. Within the packet, the waves have the vertical tilts upstream with height as a necessary condition for the release of the available potential energy in baroclinic instability. The baroclinic mechanism of the amplification is related to vertical 
(a)

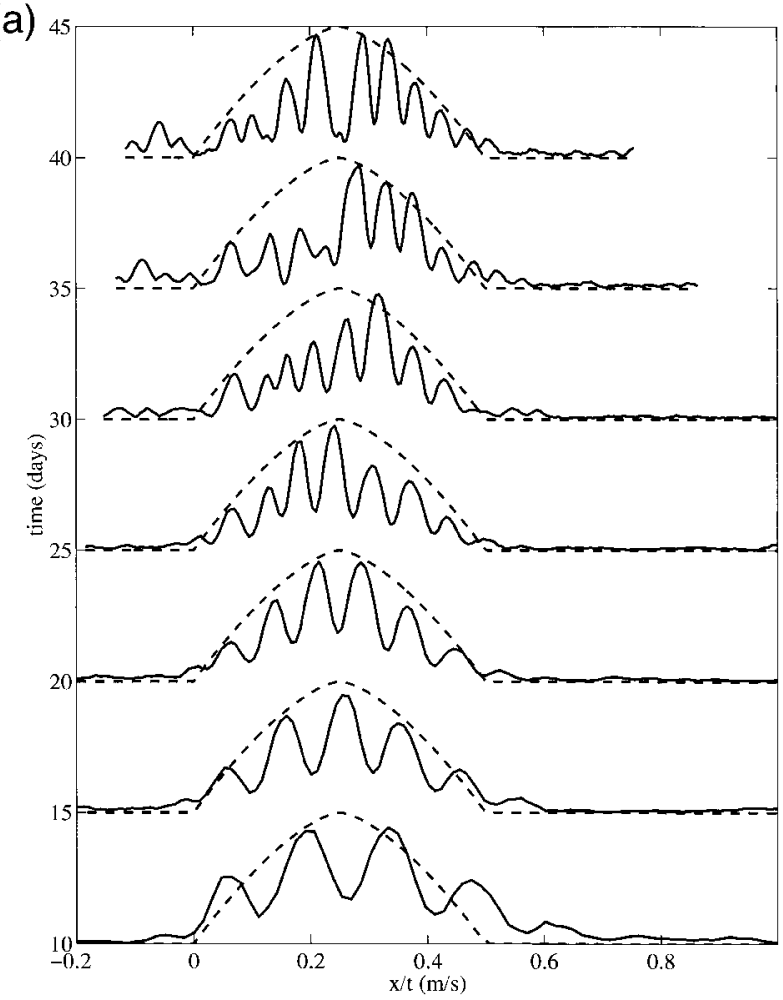

(b)

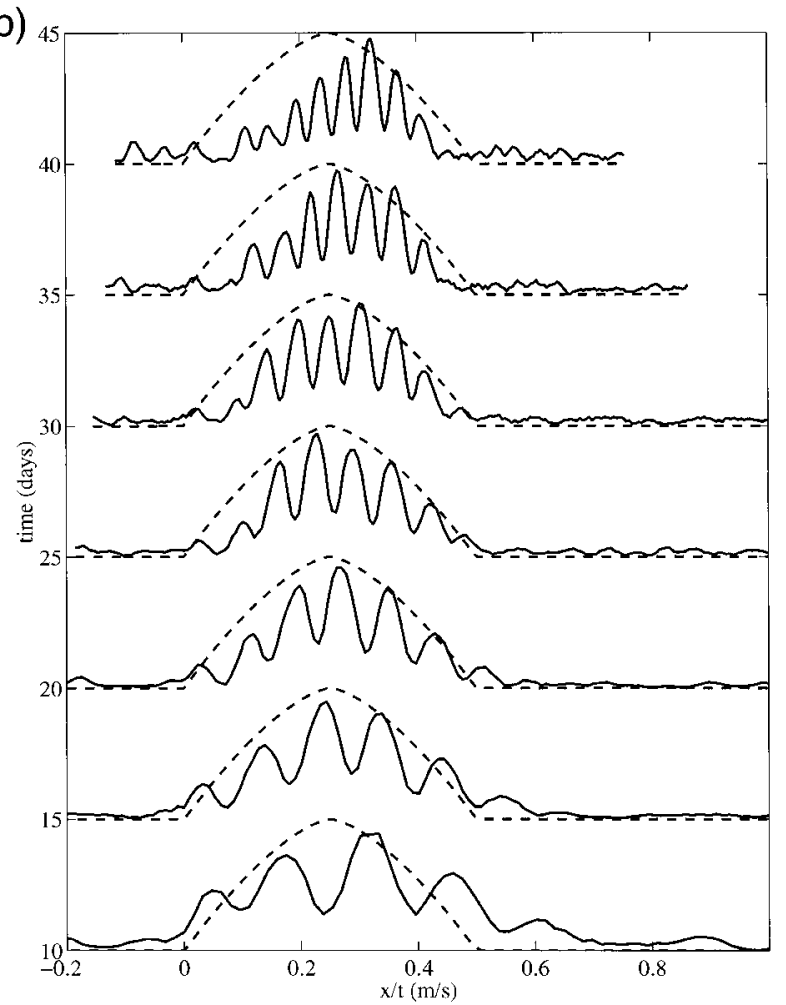

FIG. 12. Time sequence of absolute value of the cross-stream velocity as a function of $x / t$ for every 5 days on the $\beta$ plane: (a) flat bottom and (b) slope bottom. The approximation (7) is superimposed at each time.

coupling between the upper jet meanders and the deep eddies generated by stretching effects in the interior.

The results can be classified according their supercriticality $\gamma$. For high $\gamma \geq 0.87$, meanders growing over the flat bottom are able to pinch off, resembling warm and cold core rings, while in the presence of a weak bottom slope of $0.002(\gamma \leq 0.73)$, the maximum amplitudes of meanders and associated deep eddies saturate with no eddy shedding. In the flat bottom case the linear growth rate is only about 10\% larger than for the sloping bottom. Nevertheless, at the nonlinear stage the slope efficiently facilitates the saturation of meander growth via constraining the development of deep eddies underneath the jet. The three-dimensional spatiotemporal development of meanders in the sloping bottom case is qualitatively similar to the baroclinic instability amplification considered by Swanson and Pierrehumbert (1994) in a simple two-layer QG model on the $\beta$ plane with a flat bottom. In their case of supercriticality $(\gamma=$ $0.6)$ the $\beta$ effect alone efficiently narrowed the zone favorable for baroclinic instability in the lower layer.

In the sloping bottom cases, meander amplitudes decay behind the packet peak, while the deep eddies merge and form a nearly zonal flow. This flow increases the barotropic transport at the warm side and generates a recirculation that is more pronounced at the cold side. The cross-stream asymmetry of the zonal flow in the lower layer beneath the frontal zone found in these cases is qualitatively consistent with the numerical results obtained by Wood (1988) and Boss and Thompson (1999) for periodic perturbations with finite Rossby number on the $\beta$ plane with a flat bottom. Thus, in the presence of a slope a mature wave packet leaves behind an equilibrated state with asymmetrically modified mean jet structure. The main equilibration mechanism is a homogenization of the lower-layer PV by the deep eddies. The width of the homogenized zone is narrower for larger slope and/or on the $\beta$ plane.

Our results also demonstrate that the baroclinic instability in all cases is predominantly convective, as there is no noticeable upstream propagation of the perturbations. Meanders grow as they propagate downstream, and their properties correspond to the results of the analysis of observational data (Lea and Cornillon 1996). The dominant wavelength is nearly the same in all our experiments [approximately $300 \mathrm{~km}$ as seen in Fig. 4 and Fig. 6, that is, slightly less than observed fastest-growing wavelength $(350 \mathrm{~km})]$. The ratio of $\sigma /$ $k$ at the observed fastest-growing wavelength, $0.23 \mathrm{~m}$ $\mathrm{s}^{-1}$, agrees with the group velocity of the packet peak shown in Fig. 12. This value is more than twice the phase speed at the fastest growing wavelength, $0.1 \mathrm{~m}$ $\mathrm{s}^{-1}$, in both observations and our experiments (see Fig. 11). The maximum growth rate (Fig. 7) at the linear 
TABLE A1. PVG-model initialization parameters.

\begin{tabular}{|c|c|c|c|c|c|}
\hline & \multicolumn{5}{|c|}{ Layer number $i$} \\
\hline & 1 & 2 & 3 & 4 & 5 \\
\hline Potential density $\rho_{i}$ & 26.37 & 27.03 & 27.50 & 27.73 & 27.80 \\
\hline Mean thickness $D_{i}(\mathrm{~m})$ & 400 & 300 & 300 & 330 & 4000 \\
\hline Thickness change $h_{i}(\mathrm{~m})$ [defined as in (9)] & 300 & 100 & 0 & -80 & 0 \\
\hline Width of the transition zone $W_{i}(\mathrm{~km})$ & 35 & 15 & 0 & 35 & 0 \\
\hline Position of the transition zone $Y_{i}(\mathrm{~km})$ & 0 & 15 & 0 & 30 & 0 \\
\hline
\end{tabular}

stage is found to be close to the value of $\sigma_{\max }=0.14$ day $^{-1}$ predicted by a two-layer baroclinic instability model over topography (Orlansky 1969). The smaller value of observed $\sigma_{\max }\left(0.09\right.$ day $\left.^{-1}\right)$ found by Lea and Cornillon (1996) for meanders below the average amplitude may be due to effects of the deep flow in the Gulf Stream system, which is initially absent in our experiments.

The role of a topographic slope in our idealized experiments exhibit several features that are consistent with Gulf Stream observations:

1) Maximum meander amplitude increases as a topographic slope relaxes, supporting observations that meander amplitudes increase downstream of Cape Hatteras where the Gulf Stream flows into the deep ocean over a weakly sloping bottom that decreases towards the Grand Banks from 0.005 at $73^{\circ} \mathrm{W}$ to $\sim 0.002$ at $70^{\circ} \mathrm{W}$ (Kontoyannis 1997).

2) A topographic slope modifies the evolution of the deep eddies and causes the phase displacement of the deep eddies in the direction of the upper layer troughs/crests, thus limiting growth of the meanders. This phase locking of the meanders with the deep eddies underneath agrees qualitatively with the observational data at the SYNOP central array (Watts et al. 1995).

3) The increase of the barotropic transport on the warm side of the jet and the generation of a recirculation on the cold side of the jet is consistent with observations in the Gulf Stream system downstream of Cape Hatteras (Johns et al. 1995).

Although our model experiments were designed without many important Gulf Stream attributes (wind forcing, realistic variable topography, interaction with other currents, etc.), the results of this study have general implications for the way the Gulf Stream system and similar western boundary currents should be dynamically interpreted. The nonlinear topographic control of the jet meanders indicates the importance of proper initialization of deep flows for adequate prediction of the Gulf Stream path evolution. The mean-flow modification resulting from the development of baroclinic instability should be an inherent feature of more realistic Gulf Stream studies, which we plan in future.

Acknowledgments. The authors would like to thank R. Watts for his comments and stimulating discussions.
We appreciate valuable comments of reviewers. This work was supported by the Office of Naval Research.

\section{APPENDIX}

\section{Gulf Stream-type Jet Representation}

In this study a Gulf Stream-type jet is represented by PV gradients in five layers. Within each layer, PV is defined (without the $\beta$ effect and topography) as

$$
Q_{i}=\frac{f+\zeta_{i}}{D_{i}+\eta_{i}-\eta_{i+1}},
$$

where $i$ is the layer number increasing downward, $f$ is the Coriolis parameter, $\zeta_{i}$ is relative vorticity vertically averaged within the layer, $D_{i}$ is mean layer thickness, and $\eta_{i}$ is displacement of the interface between $i$ and $i$ - 1 layers. The following layer subdivision is prescribed [we follow partly the scheme given in Hall and Fofonoff (1993) and Logoutov et al. (2001)].

1) Noninsulated layer: $\sigma_{\theta}<26.00$. Subjected to heat and freshwater fluxes from the sea surface. The PV is not conserved in this layer.

2) The $18^{\circ}$ Water layer: $\sigma_{\theta}=26.00-26.75$. The layer of a strong PV change across the front. The limits are chosen such that the PV gradient in the frontal zone is approximately of the same value vertically through the layer.

3) The upper main thermocline layer: $\sigma_{\theta}=26.75-$ 27.30. The buffer layer between the upper layer with a strong cross-stream PV change and underneath layer of nearly uniform cross-stream PV.

4) The main thermocline layer: $\sigma_{\theta}=27.30-27.70$. Dynamically active layer with nearly uniform crossstream PV.

5) The lower main thermocline layer: $\sigma_{\theta}=27.70$ 27.76. The layer of the reversed sign (negative) PV gradient.

6) The quasi-barotropic layer: $\sigma_{\theta}>27.76$. Deep layer with nearly barotropic motion because of weak stratification.

A Gulf Stream-type PV front is represented as a transition area between two water masses with different stratifications prescribed by the layer thickness difference, $2 h_{i}$, between the two sides in each layer. Thus, the potential vorticity on the one side is $Q_{i}=f /\left(D_{i}-\right.$ $\left.h_{i}\right)$, while on the other side it is $Q_{i}=f /\left(D_{i}+h_{i}\right)$. In 
this paper we focus on baroclinic instability so that within each layer, except the lowest one, we use a PV-gradient model (Logoutov et al. 2001) assuming that the

$$
q_{i}=\left\{\begin{array}{l}
\frac{D_{i}}{D_{i}+h_{i}} \\
D_{i}\left(D_{i}+h_{i} \sin \frac{2\left(Y_{i}-y\right)}{W_{i}}\right)^{-1} \\
\frac{D_{i}}{D_{i}-h_{i}}
\end{array}\right.
$$

for $y \leq Y_{i}-\frac{\pi W_{i}}{4}$,

for $Y_{i}-\frac{\pi W_{i}}{4}<y<Y_{i}+\frac{\pi W_{i}}{4}$,

for $y \geq Y_{i}+\frac{\pi W_{i}}{4}$, width $W_{i}$, as where $Y_{i}$ is the cross-stream position of the frontal zone.

In order to invert the prescribed PV into the corresponding velocity and density fields we use the geostrophic relation

$$
\zeta_{i}=-\frac{d U_{i}}{d y}=\frac{1}{f \rho_{i}} \frac{d^{2} P_{i}}{d y^{2}}
$$

and the hydrostatic approximation to express the interface displacement through the pressure anomaly $P_{i}$ vertically averaged within each layer:

$$
P_{i+1}-P_{i}=g \eta_{i+1}\left(\rho_{i+1}-\rho_{i}\right) .
$$

Here $\rho_{i}$ and $\rho_{i+1}$ are the vertically averaged potential density in the layer $i$ and $i+1$, correspondingly.

Combining Eqs. (A1), (A3), and (A4), we obtain an elliptic system of equations to calculate the pressure anomalies in each layer:

$$
\begin{gathered}
\frac{1}{\rho_{i} f^{2}} \frac{d^{2} P_{i}}{d y^{2}}+\frac{Q_{i}}{g f}\left(\frac{P_{i+1}-P_{i}}{\rho_{i+1}-\rho_{i}}+\frac{P_{i-1}-P_{i}}{\rho_{i}-\rho_{i-1}}\right)=\frac{Q_{i} D_{i}}{f}-1 \\
i=1,2, \cdots, M .
\end{gathered}
$$

For $M$ active layers we assume no motion in the bottom layer $\left(P_{M+1}=0\right)$ and a rigid-lid approximation at the surface $\left(P_{1}=P_{0}\right)$. Corresponding horizontal boundary conditions far from the jet are

$$
\begin{aligned}
& P_{i}=g \sum_{k=i}^{M} \eta_{k+1}\left(\rho_{k+1}-\rho_{k}\right) \quad \text { at } y \rightarrow-\infty \\
& P_{i}=-g \sum_{k=i}^{M} \eta_{k+1}\left(\rho_{k+1}-\rho_{k}\right) \quad \text { at } y \rightarrow+\infty,
\end{aligned}
$$

where $\eta_{k+1}=\sum_{l=1}^{k} h_{l}$.

When $\left|Q_{i} D_{i} / f-1\right| \ll 1$, the coefficients on the lefthand side of (A5) are considered to be independent of horizontal coordinates so the solution can be decomposed into vertical modes and expressed analytically. We cannot use this (quasigeostrophic) approximation since $\left|Q_{i} D_{i} / f-1\right|>1$ in the upper Gulf Stream layers. Instead, we use a successive over-relaxation iteration potential vorticity changes monotonically across the jet and its gradient is concentrated in a frontal zone of finite

technique to solve the problem numerically with the above boundary conditions.

The specified parameters in each layer are shown in Table A1. They are chosen to fit the observed velocity in the Gulf Stream as described by Logoutov et al. (2001).

\section{REFERENCES}

Blumberg, A. F., and G. L. Mellor, 1987: A description of a threedimensional coastal ocean circulation model. Three-Dimensional Coastal Ocean Model, N. Heapes, Ed., Vol. 4, Coastal and Estuarine Sciences, Amer. Geophys. Union, 1-16.

Blumsack, S., and P. J. Gierasch, 1972: Mars: The effects of topography on baroclinic stability. J. Atmos. Sci., 29, 1081-1089.

Boss, E., and L. Thompson, 1999: Mean flow evolution of a baroclinically unstable potential vorticity front. J. Phys. Oceanogr., 29, 273-287.

__, N. Paldor, and L. Thompson, 1996: Stability of a potential vorticity front: From quasi-geostrophy to shallow water. J. Fluid Mech., 315, 65-84.

Bush, A. B. G., J. C. McWilliams, and W. R. Peltier, 1995: The formation of oceanic eddies in symmetric and asymmetric jets. Part I: Early time evolution and bulk eddy transports. J. Phys. Oceanogr., 25, 1959-1979.

$\ldots, \ldots$, and —_ 1996: The formation of oceanic eddies in symmetric and asymmetric jets. Part II: Late time evolution and coherent vortex formation. J. Phys. Oceanogr., 26, 1825-1848.

Cornillon, P., D. Evans, and W. Large, 1986: Warm outbreaks of the Gulf Stream into the Sargasso Sea. J. Geophys. Res., 91, 65836596.

de Szoeke, R. A., 1975: Some effects of bottom topography on baroclinic instability. J. Mar. Res., 33, 93-122.

Eady, E. T., 1949: Long waves and cyclone waves. Tellus, 1, 33-52.

Farrell, B. F., 1982: Pulse asymptotics of the Charney baroclinic instability problem. J. Atmos. Sci., 39, 507-517.

Flierl, G. R., 1999: Thin jet and contour dynamics models of Gulf Stream meandering. Dyn. Atmos. Oceans, 29, 189-215.

Fofonoff, N. P., 1981: The Gulf Stream system. Evolution of Physical Oceanography, B. A. Warren and C. Wunsch, Eds., The MIT Press, 112-139.

Halkin, D., and H. T. Rossby, 1985: The structure and transport of the Gulf Stream at $73^{\circ}$ W. J. Phys. Oceanogr., 15, 1439-1452.

Hall, M. M., and N. P. Fofonoff, 1993: Downstream development of the Gulf Stream from $68^{\circ}$ to $55^{\circ}$ W. J. Phys. Oceanogr., 23, 225249.

Holland, W. R., and D. B. Haidvogel, 1980: A parameter study of 
the mixed instability of idealized ocean currents. Dyn. Atmos. Oceans, 4, 185-215.

Huerre, P., and P. A. Monkewitz, 1990: Local and global instabilities in spatially developing flows. Annu. Rev. Fluid Mech., 22, 473 537.

Ikeda, M., 1981: Meanders and detached eddies of a strong eastwardflowing jet using a two-layer quasigeostrophic model. J. Phys. Oceanogr., 11, 526-540.

___, and J. R. Apel, 1981: Mesoscale eddies detached from spatially growing meanders in an eastward-flowing oceanic jet using a two-layer quasi-geostrophic model. J. Phys. Oceanogr., 11, 1638-1661.

Johns, W. E., T. J. Shay, J. M. Bane, and D. R. Watts, 1995: Gulf Stream structure, transport, and recirculation near $68^{\circ} \mathrm{W}$. J. Geophys. Res., 100, 817-838.

Killworth, P. D., 1980: Barotropic and baroclinic instability in rotating stratified fluids. Dyn. Atmos.-Oceans, 4, 143-184.

Kontoyannis, H., 1997: Quasi-geostrophic modeling of mixed instabilities in the Gulf Stream neat $73^{\circ}$ W. Dyn. Atmos.-Oceans, 26, 133-158.

Lea, T., and P. Cornillon, 1996: Propagation of Gulf Stream meanders between $75^{\circ}$ and $45^{\circ} \mathrm{W}$. J. Phys. Oceanogr., 26, 225-241.

Leaman, K. D., E. Johns, and T. Rossby, 1989: The average distribution of volume transport and potential vorticity with temperature at three sections across the Gulf Stream. J. Phys. Oceanogr., 19, 36-51.

Logoutov, O. G., G. G. Sutyrin, and D. R. Watts, 2001: Potential vorticity structure across the Gulf Stream: Observations and a PV-gradient model. J. Phys. Oceanogr., 31, 637-644.

Luther, M. E., and J. M. Bane, 1985: Mixed instabilities in the Gulf Stream over the continental slope. J. Phys. Oceanogr., 15, $3-$ 23.

Meacham, S. P., 1991: Meander evolution on quasigeostrophic jets. J. Phys. Oceanogr., 21, 1139-1170.

Mechoso, C. R., 1980: Baroclinic instability of flows along sloping boundaries. J. Atmos. Sci., 37, 1393-1399.

—_, and D. M. Sinton, 1981: Instability of baroclinic flows with horizontal shear along topography. J. Phys. Oceanogr., 11, 813821.

Mellor, G. L., 1998: User's guide for a three-dimensional, primitive equation, numerical ocean model. Atmospheric and Oceanic Sciences Program, Princeton University, $39 \mathrm{pp}$.

—_ and T. Yamada, 1982: Development of a turbulent closure model for geophysical fluid problem. Rev. Geophys. Space Phys., 20, $851-875$.

Mysak, L. A., E. R. Johnson, and W. W. Hsieh, 1981: Barotropic and baroclinic instabilities of coastal currents. J. Phys. Oceanogr., 11, 209-230.

Nakamura, N., 1993: Momentum flux, flow symmetry, and the nonlinear barotropic governor. J. Atmos. Sci., 50, 2159-2179.

Orlansky, I., 1969: The influence of bottom topography on the stability of jets in a baroclinic fluid. J. Atmos. Sci., 26, 1216-1232.

Pedlosky, J., 1970: Finite-amplitude baroclinic waves. J. Atmos. Sci., 27, 15-30.

Phillips, N. A., 1954: Energy transformations and meridional circulations associated with simple baroclinic waves in a two-level, quasigeostrophic model. Tellus, 6, 273-286.

Pierrehaumbert, R. T., and K. L. Swanson, 1995: Baroclinic instability. Annu. Rev. Fluid Mech., 27, 419-467.

Polovarapu, S. M., and W. R. Peltier, 1990: The structure and non- linear evolution of synoptic scale cyclones: Life cycle simulations with a cloud-scale model. J. Atmos. Sci., 47, 2645-2672.

Pratt, L. J., and M. E. Stern, 1986: Dynamics of potential vorticity fronts and eddy detachment. J. Phys. Oceanogr., 16, 1101-1120.

Rhines, P. B., 1977: The dynamics of unsteady currents. The Sea. Vol. 6: Marine Modeling, E. D. Goldberg, Ed., John Wiley and Sons, 189-318.

Robinson, A. R., J. R. Luyten, and F. C. Fuglister, 1974: Transient Gulf Stream meandering. Part I: An observational experiment. J. Phys. Oceanogr., 4, 237-255.

— M. A. Spall, and N. Pinardi, 1988: Gulf Stream simulations and the dynamics of ring and meander process. J. Phys. Oceanogr., 18, 1811-1853.

Shepherd, T. G., 1983: Mean motions induced by baroclinic instability in a jet. Geophys. Astrophys. Fluid Dyn., 27, 35-72.

Simmons, A. J., and B. J. Hoskins, 1980: Barotropic influences on the growth and decay of nonlinear baroclinic waves. J. Atmos. Sci., 37, 1679-1684.

Smagorinsky, J., 1963: General circulation experiments with primitive equations: I. The basic experiments. Mon. Wea. Rev., 91, 291-304.

Spall, M. A., and A. R. Robinson, 1990: Regional primitive equation studies of the Gulf Stream meander and ring formation region. J. Phys. Oceanogr., 20, 985-1016.

Stommel, H., 1965: The Gulf Stream: A Physical and Dynamical Description. 2d ed. University of California Press, $248 \mathrm{pp}$.

Straneo, F., and N. Pinardi, 1994: Deep thermocline eddies in the proximity of the Gulf Stream. A numerical study. Course on Geophysical Fluid Dynamics, International Centre for Theoretical Physics, 1-38.

Sutyrin, G. G., and I. G. Yushina, 1989: Numerical modelling of the formation, evolution, interaction, and decay of isolated vortices. Mesoscale/Synoptic Coherent Structures in Geophysical Turbulence, J. C. J. Nihoul and B. M. Jamart, Eds., Elsevier Oceanogr. Series, Vol. 50, Elsevier, 721-736.

Swanson, K., and R. T. Pierrehumbert, 1994: Nonlinear wave packet evolution on a baroclinically unstable jet. J. Atmos. Sci., 51, 384-396.

Tang, C. M., 1976: The influence of meridionally slopping topography on baroclinic instability and its implications for macroclimate. J. Atmos. Sci., 33, 1515-1525.

Thorncroft, C. D., B. J. Hoskins, and M. E. McIntyre, 1993: Two paradigms of baroclinic-wave life-cycle behavior. Quart. J. Roy. Meteor. Soc., 119, 17-55.

Wang, J., and M. Ikeda, 1997: Diagnosing ocean unstable baroclinic waves and meanders using the quasigeostrophic equations and Q-vector method. J. Phys. Oceanogr., 27, 1158-1172.

Watts, D. R., K. L. Tracey, J. M. Bane, and T. J. Shay, 1995: Gulf Stream path and thermocline structure near $74^{\circ} \mathrm{W}$ and $68^{\circ} \mathrm{W}$. $J$. Geophys. Res., 100, 18 291-18 312.

Wood, R. A., 1988: Unstable waves on oceanic fronts: Large amplitude behavior and mean flow generation. J. Phys. Oceanogr., 18, 775-787.

Wright, D. G., 1980a: On the stability of a fluid with specialized density stratification. Part I: Baroclinic instability and constant bottom slope. J. Phys. Oceanogr., 10, 639-666.

— 1980b: On the stability of a fluid with a specialized density stratification. Part II: Mixed baroclinic-barotropic instability with application to the northeast Pacific. J. Phys. Oceanogr., 10, 1307-1322.

Xue, H., and G. Mellor, 1993: Instability of the Gulf Stream front in the South Atlantic Bight. J. Phys. Oceanogr., 23, 2326-2350. 